\title{
Non-invasive methods for the determination of body and carcass composition in livestock: dual-energy X-ray absorptiometry, computed tomography, magnetic resonance imaging and ultrasound: invited review
}

\author{
A. M. Scholz ${ }^{1 \dagger}$, L. Bünger ${ }^{2}$, J. Kongsro ${ }^{3}$, U. Baulain ${ }^{4}$ and A. D. Mitchell ${ }^{5}$ \\ ${ }^{1}$ Livestock Center Oberschleißheim, Ludwig-Maximilians-University Munich, Sankt-Hubertusstrasse 12, 85764 Oberschleißheim, Germany; ${ }^{2}$ SRUC, Animal and \\ Veterinary Sciences, Roslin Institute Building, Easter Bush, Midlothian, Scotland EH25 9RG, UK; ${ }^{3}$ Norsvin, Department of Animal and Aquacultural Sciences, clo \\ Norwegian University of Life Sciences, PO Box 5003, N-1432 Ås, Norway; ${ }^{4}$ Institute of Farm Animal Genetics, Friedrich-Loeffler-Institut, Hoeltystr.10, 31535 \\ Neustadt, Germany; ${ }^{5}$ Agricultural Research Service (Retired), US Department of Agriculture, 10300 Baltimore Avenue, BARC-West, Beltsville, MD 20705, USA
}

The ability to accurately measure body or carcass composition is important for performance testing, grading and finally selection or payment of meat-producing animals. Advances especially in non-invasive techniques are mainly based on the development of electronic and computer-driven methods in order to provide objective phenotypic data. The preference for a specific technique depends on the target animal species or carcass, combined with technical and practical aspects such as accuracy, reliability, cost, portability, speed, ease of use, safety and for in vivo measurements the need for fixation or sedation. The techniques rely on specific device-driven signals, which interact with tissues in the body or carcass at the atomic or molecular level, resulting in secondary or attenuated signals detected by the instruments and analyzed quantitatively. The electromagnetic signal produced by the instrument may originate from mechanical energy such as sound waves (ultrasound - US), 'photon' radiation (X-ray-computed tomography - CT, dual-energy X-ray absorptiometry - DXA) or radio frequency waves (magnetic resonance imaging - MRI). The signals detected by the corresponding instruments are processed to measure, for example, tissue depths, areas, volumes or distributions of fat, muscle (water, protein) and partly bone or bone mineral. Among the above techniques, CT is the most accurate one followed by MRI and DXA, whereas US can be used for all sizes of farm animal species even under field conditions. $C T, M R I$ and US can provide volume data, whereas only DXA delivers immediate whole-body composition results without (2D) image manipulation. A combination of simple US and more expensive CT, MRI or DXA might be applied for farm animal selection programs in a stepwise approach.

Keywords: animal, body composition, X-ray attenuation, magnetic resonance imaging, ultrasound

\section{Implications}

The ability to accurately and precisely measure body or carcass composition is important for performance testing, grading and finally the selection or payment of meatproducing animals. Advances especially in non-invasive techniques are mainly based on the development of electronic and computer-driven methods in order to provide objective phenotypic data. This review provides a summary of the recent developments in the application of dual-energy $\mathrm{X}$-ray absorptiometry, X-ray computed tomography, magnetic resonance imaging and ultrasound.

\footnotetext{
${ }^{\dagger}$ E-mail: Armin.Scholz@|vg.vetmed.uni-muenchen.de
}

\section{Introduction}

Although meat consumption in Europe and worldwide is not increasing at the same rate, meat from farm animals will continue to be the major source of protein for human nutrition throughout the world (OECD/Food and Agriculture Organization of the United Nations, 2014). In order to provide a fair and comparable payment for farmers, it is necessary to base the classification of carcasses or meat-producing animals on harmonized procedures with the least impact on the quality and quantity of the products for human consumption. Non-invasive grading or classification procedures have preference over invasive procedures like dissection or chemical analysis. The ability to accurately and precisely 
measure body composition or carcass composition is also important for applications related to PHENOTYPING in performance testing and breeding programs or scientific studies focusing on growth, nutrition, genetics, housing and behavior or farm animal well-being.

\section{Background}

Humans started to classify or select animals with the domestication of wild animals thousands of years ago. This classification and selection process was (and still is) mainly based on visual and tactile appraisal with a preference for less-aggressive and easily fed animals. Apart from selection procedures based on the form, size, weight, speed, behavior, fertility, antlers, horns or coat color, it took thousands of years until 'more' scientifically based procedures for farm animal evaluation or classification were invented. In almost all cases, farm or wild animals had or have to be sacrificed in order to be able to process the products for human consumption or utilization - with the exception of milk, egg, wool, work, company or manure. Tissue dissection, however, is still the main European reference standard for the approval of carcass classification procedures or formulas (Nissen et al., 2006').

First 'non-invasive imaging' methods on farm animals were tested by Kronacher and Hogreve (1936) and Hogreve (1938) using X-radiography in order to study the pelvis shape of different pig breeds and the adipose tissue deposition of fattening pigs, respectively. The first studies using the specific velocity of ultrasound (US; $>20 \mathrm{kHz}$ ) in different body tissues were started in meat-producing farm animals by Temple et al. (1956). More than 30 years ago, the first papers dealing with X-ray-based computed tomography (CT; Skjervold et al., 1981) and nuclear magnetic resonance imaging (tomography - MRI: Groeneveld et al., 1983; even earlier spectroscopy, Casey and Miles, 1974) for the evaluation of meat or carcass and body composition of farm animals were published. Early attempts to cope automatically with MRI inhomogeneity were made by Scholz et al. (1993) using a cluster analysis for the segmentation into fat and muscle tissue of pigs in vivo only after defining a region of interest of the body part MR scanned. The first dualenergy X-ray absorptiometry (DXA) studies - especially regarding farm animal body composition - started with Mitchell et al. (1996).

Since then, technical progress continued providing 'bigger, quicker and smarter' non-invasive imaging or scanning devices for the determination of body and/or carcass composition measurements in farm animal selection programs. Besides Australia, New Zealand, Norway and the United Kingdom, quite a few countries like, for example, Austria, Canada, Denmark, France, Germany, Hungary, Ireland, Spain, Sweden and the United States of America use(d) CT (e.g. Junkuszew and Ringdorfer, 2005; Romvari et al., 2006; Font-i -Furnols and Gispert, 2009; Vester-Christensen et al., 2009; Picouet et al., 2010) or MRI (e.g. Mitchell et al., 2001; Collewet et al., 2005; Monziols et al., 2006; Margeta et al., 2007;

${ }^{1}$ References before 2010 in Supplementary Material S1.
Baulain, 2013) as the reference technology for carcass grading in abattoirs (e.g. Branscheid et al., 2011; Daumas et al., 2013) or for performance testing in farm animal breeding programs (e.g. sheep: von Korn et al., 2005; Baulain et al., 2011; rabbits: Nagy et al., 2010; Gyovai et al., 2012; Szendrő et al., 2012; pigs: McEvoy et al., 2009; Kremer et al., 2012, 2013; broiler: Davenel et al., 2000; Milisits et al., 2013; laying hens: Szentirmai et al., 2013; and turkeys: Andrássy-Baka et al., 2003).

Owing to changes in carcass confirmation caused by breeding progress in various farm animal populations, differences among breeds/species themselves or gender-specific carcass composition, there is a steady need for newly derived or adapted formulas for the (S)EUROP classification in carcass grading (Baulain et al., 2003; Branscheid et al., 2011; Monziols et al., 2013) or for performance testing (Tholen et al., 2003; Bernau et al., 2013 and 2015). This is necessary as long as no whole-body or whole-carcass information would be used (Kongsro et al., 2008).

\section{Non-invasive techniques for body/carcass composition measurements}

A common feature of non-invasive techniques for body or carcass composition measurements is that they work with electromagnetic or mechanical energies, which are able to pass completely or partially through body or carcass tissues such as muscle (lean meat $=$ protein + water), adipose tissue (fat, lipids) and bone. Figure 1 summarizes the different (electromagnetic) energy levels that are being used for a number of non-invasive measurement techniques.

All techniques shown in Figure 1 rely on specific devicedriven signals, which interact with tissues in the body or carcass at the atomic or molecular level, resulting in secondary or attenuated signals detected by the instruments and analyzed quantitatively. The signal (energy) produced by the instrument may be in the form of sound waves (US), X-radiation (e.g. CT and DXA) or radio frequency (RF) waves (MRI). The signals detected by these instruments are processed to measure, for example, tissue depths, areas, volumes or distributions of fat, muscle (water, protein) and partly bone or bone mineral (Table 1).

In many cases, these metrology results have to be compared with or validated against a (SI) reference standard directly derived from the carcass. The difference between the arithmetic mean from the non-invasive technique and the arithmetic mean of the reference provides a measure of BIAS or trueness. In addition, the (adjusted) coefficient of determination or regression coefficient $\left(R^{2}\right)$ combined with an error term or term of uncertainty serves as a statistically defined term of accuracy (i.e. precision). For example, partly depending on the statistical modeling procedure, the root mean squared error of estimation and/or prediction or (cross) validation sometimes standardized as residual standard deviation (root mean squared error divided by the standard deviation of the reference mean) provide information about the uncertainty if compared with a reference technique (Johansen et al., 2007, e.g. Table 2). A standard description 
Scholz, Bünger, Kongsro, Baulain and Mitchell

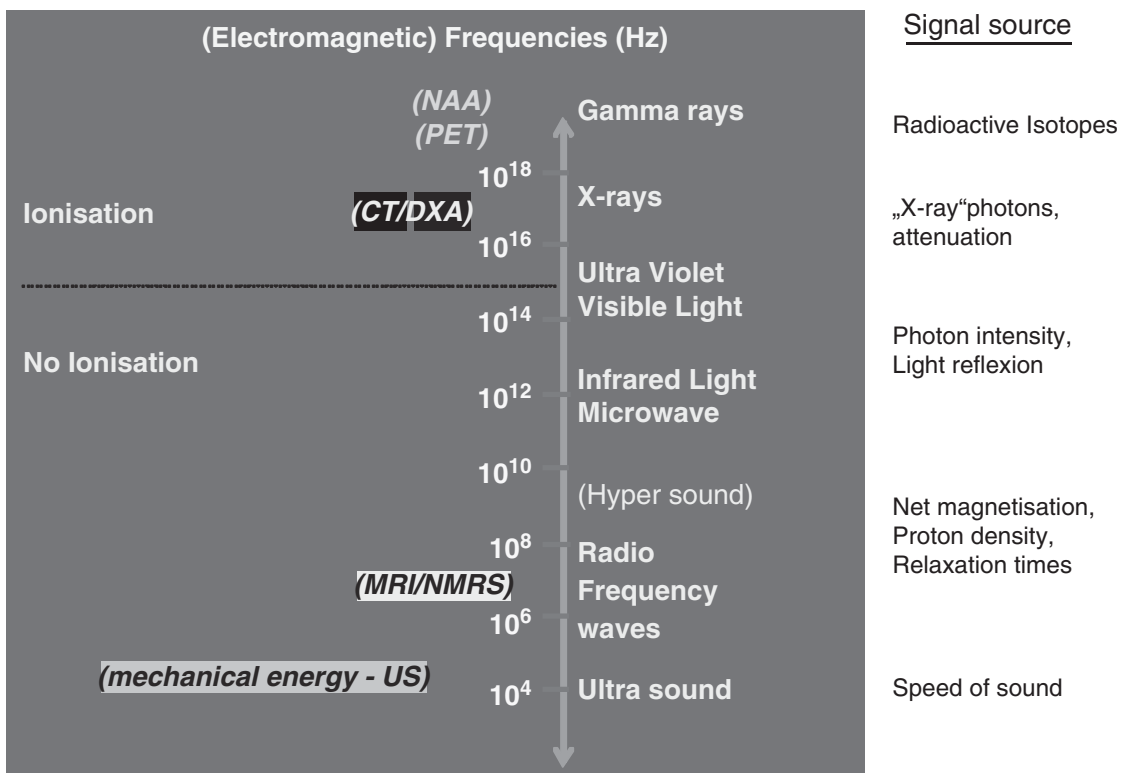

Figure 1 Overview of imaging methods.

Table 1 Traits determined by non-invasive techniques

\begin{tabular}{ll}
\hline \hline Non-invasive technique & Trait \\
\hline Dual-energy X-ray absorptiometry (DXA) & Photon number passage (tissue level) \\
& X-ray attenuation coefficient from two energy levels \\
& Bone mineral content \\
& Bone mineral area \\
& Bone mineral density \\
& Soft tissue mass \\
& Lean tissue mass \\
& Fat tissue mass \\
& Whole-body and regional data \\
& Photon number passage (tissue level) \\
& X-ray attenuation in Hounsfield units (HU) \\
& Tissue areas or volumes depending on anatomical position and HU \\
Computed tomography (CT) & Regional and whole-body data \\
& Nuclear magnetic resonance pattern (atomic level) \\
& Energy level (net magnetization) of nuclei with uneven proton and neutron number \\
Magnetic resonance imaging (MRI) & Longitudinal and transversal relaxation times \\
& Proton density \\
Tissue areas or volumes depending on anatomical position and (arbitrary) signal intensities \\
Regional and whole-body data \\
Speed of (ultra) sound (tissue level) \\
Mechanical energy level $v$. electrical energy level \\
Signal amplitude, signal brightness \\
Regional distances, areas, volumes \\
\hline
\end{tabular}

is provided by ISO 5725 (https://www.iso.org/obp/ui/\#iso:std: iso:5725:-1:ed-1:v1:en). If two techniques are being compared without a 'gold standard' or 'true' reference, an improved Bland-Altman analysis might be the first choice as the statistical procedure (Liao and Capen, 2011).

Several publications summarize further invasive or noninvasive methods that are not considered in this review. Simeonova et al. (2012), for example, provide a recent review focusing on methods for determining pig body composition, especially on protein deposition during growth. All 'radiology' applications reviewed in this paper are based on the inventions and findings of a number of scientists and engineers summarized in the book Classic Papers in Modern Diagnostic Radiology.

DXA

Both the techniques, CT and DXA, are based on the measurement of the attenuation of X-rays (photons) passing 
DXA, CT, MRI and US in farm animals

Table 2 Relationship between carcass composition from dissection and DXA carcass or in vivo body composition, depending on species (pig, sheep, cattle) studied (all whole-body DXA data from the same GE Lunar DPX-IQ scanner ${ }^{1}$ )

\begin{tabular}{|c|c|c|c|c|c|c|c|c|c|}
\hline \multirow[b]{2}{*}{ Dissection v. DXA } & \multicolumn{3}{|c|}{$\begin{array}{c}\operatorname{Pig}(n=61) \\
R^{2}(\sqrt{\text { m.s.e. } / \text { s.d. })}\end{array}$} & \multicolumn{3}{|c|}{$\begin{array}{c}\text { Lamb }(n=93) \\
R^{2}(\sqrt{ } \text { m.s.e./s.d. })\end{array}$} & \multicolumn{3}{|c|}{$\begin{array}{c}\text { Calf }(n=34) \\
R^{2}(\sqrt{ } \text { m.s.e./s.d. })\end{array}$} \\
\hline & & Carcass & In vivo & & Carcass & In vivo & & Carcass & In vivo \\
\hline Reference & CV & & & CV & & & CV & & \\
\hline FAT (\%) & 0.19 & $0.80(0.46)$ & $0.74(0.46)$ & 0.22 & $0.73(0.52)$ & $0.51(0.69)$ & 0.14 & $0.28(0.86)$ & $0.003(1.02)$ \\
\hline FAT (g) & 0.28 & $0.90(0.32)$ & $0.89(0.43)$ & 0.31 & $0.83(0.42)$ & $0.71(0.27)$ & 0.23 & $0.64(0.78)$ & $0.42(0.39)$ \\
\hline Meat (\%)/soft lean (\%) & 0.05 & $0.70(0.57)$ & $0.65(0.64)$ & 0.04 & $0.57(0.66)$ & $0.50(0.70)$ & 0.04 & $0.53(0.69)$ & $0.09(0.97)$ \\
\hline Meat $(\mathrm{g}) / \mathrm{soft}$ lean $(\mathrm{g})$ & 0.14 & $0.94(0.39)$ & $0.82(0.55)$ & 0.10 & $0.88(0.35)$ & $0.57(0.33)$ & 0.23 & $0.98(0.13)$ & $0.94(0.12)$ \\
\hline
\end{tabular}

DXA = dual-energy X-ray absorptiometry.

${ }^{1}$ This is the only known comparison for the three livestock species using the same DXA device always to compare carcass and in vivo data with reference dissection, modified from Scholz et al. (2013).

through a body (in vivo) or a carcass (postmortem). Tissues or elements in the body or carcass are characterized by specific mass attenuation coefficients, depending on the photon energy level being applied for the measurement. DXA and a combination of DXA and CT (dual-energy X-ray computed tomography - DECT; see Johnson, 2009; Magnusson et al., 2011) are based on the application of two different X-ray photon energy levels (high and low), whereas CT works (simplified) only with one (monochromatic) X-ray photon energy level (Kalender, 1988). The ratio (by using the natural logarithm $=\ln$ ) of the attenuated $(I)$ and the initial X-ray photon number $\left(I_{O}\right)$ for the low $(L)$ and the high $(H)$ energy levels provides the so-called $R$ value (X-ray attenuation coefficient). This $R$ value is - depending on the energy levels used - a unique trait for a certain element or compound tissues, such as bone mineral, soft, lean or fat tissues (Crabtree et al., 2007; Wang et al., 2010). Different generations of DXA (or CT) machines use either pencil or fan-beam technology. The fan-beam technology has been extended to a so-called cone-beam or a flash-beam technique. A wholebody scan with a rather slow but very accurate pencil-beam scanner could take up to $35 \mathrm{~min}$, whereas a whole-body scan with a high-speed cone-beam scanner takes $<3$ min. Different manufacturers of DXA (or DECT) scanners use different approaches to create a high and a low X-ray energy levels (Ulzheimer and Flohr, 2009). Therefore, DXA needs crossvalidation for transferring composition results among devices and software modes (Plank, 2005; Scholz et al., 2007 and 2013; Hull et al., 2009; Lösel et al., 2010). In addition, DXA as an indirect tool (Dunshea et al., 2007; Scholz and Mitchell, 2010; Hunter et al., 2011) does not provide a measure of the lean meat percentage. It is still necessary to determine the accuracy of DXA by reference dissection or chemical analysis. The wholebody/carcass composition estimate is available immediately after the scan is completed. Alone, a regional analysis in order to quantify the 2D tissue distribution requires manual manipulation time, depending on the number and anatomical specification of the regions of interest.

DXA studies have been performed on a large variety of farm animal species such as pigs (or pork): Mitchell et al. (2000 and 2003); Scholz et al. (2002); Suster et al. (2004);
Marcoux et al. (2005); Scholz and Förster (2006); Latorre et al. (2008); Kremer et al. (2012, 2013); Kogelman et al. (2013); chicken/broiler/eggs: Swennen et al. (2004); Schreiweis et al. (2005); England et al. (2012); Salas et al. (2012); turkeys: Schöllhorn and Scholz (2007); sheep (or lamb carcasses): Mercier et al. (2006); Hopkins et al. (2008), Ponnampalam et al. (2008); Pearce et al. (2009); Hunter et al. (2011); Scholz et al. (2013); calves/calf carcasses: Bascom (2002); Scholz et al. (2003); Hampe et al. (2005); fish: Wood (2004), or beef: Ribeiro et al. (2011); as well as in the wool and meat industry: Kröger et al. (2006) and Ho et al. (2013).

The accuracy of DXA measurements comparing pigs, lambs, calves and turkeys has been summarized recently by Scholz et al. (2013). To our knowledge, this is the only comparison performed always with the same GE Lunar DPXIQ (GE Healthcare, Oskar-Schlemmer-Strasse 11, D-80807 München) machine (Table 2). Accuracies for turkeys $(n=100)$ measured with the same GE Lunar DPX IQ pencilbeam scanner comparing DXA carcass with chemical analysis data resulted in the following coefficients of determination as are for fat $(\%): R^{2}=0.74(\sqrt{ }$ m.s.e. $=2.11)$, fat $(\mathrm{g})$ : $R^{2}=0.86(\sqrt{ }$ m.s.e. $=254)$, protein + water $v$. soft lean $(\%)$ : $R^{2}=0.69(\sqrt{ }$ m.s.e. $=2.33)$ and protein + water $v$. soft lean (g): $R^{2}=0.99(\sqrt{ }$ m.s.e. $=178)($ data from Kreuzer, 2008). The accuracy (low $R^{2}$, high r.s.d.) for lean meat percentage in calves (Table 2) is rather low due to the relatively low variability in the lean meat percentage of the young calves in comparison with the relatively high variability of the lean tissue weight especially in vivo. The error (inaccuracy) is even inflated during reference dissection, especially by the individual butcher effect (Nissen et al., 2006). The relatively low absolute amount of fat leads to relatively large errors in percentage values for lean and fat tissues. The main difference among calves originates from different BWs causing variations in lean tissue weight. Bascom (2002) concluded that DXA is not suitable for the prediction of the percentage of carcass fat or carcass $C P$ in Jersey calves (adjusted $R^{2}<0.1$ ), although it is unclear what was done during that study in terms of the DXA analysis. Dunshea et al. (2007) found higher prediction accuracies for chemically determined reference carcass composition in sheep with $R^{2}$ of 0.98 for lean weight and of 0.94 for lean percentage. In addition, 
Hunter et al. (2011) stated that DXA-derived estimates of total and individual tissue masses are highly related to, and can be used to predict, chemical composition in vivo or of whole carcasses and carcass halves (in sheep). An adjustment of the prediction equations, however, depends in all cases on the manufacturer (General Electrics, Hologic, Norland, Diagnostic Medical Systems), species, age or weight, software mode and animal positioning on the scan table.

\section{$C T$}

Contrary to DXA and DECT, CT works with only one (monochromatic) X-ray level (Kalender, 2006). The mass attenuation coefficient of the object (tissue) of interest is transformed into the so-called Hounsfield units (HU) or CT values by taking the mass attenuation for water and air into account. The almost-fixed range of $\mathrm{HU}$ for a given tissue could be used for (fully) automated image segmentation, distinguishing among the body tissue fat, muscle (water) and bone (Glasbey et al., 1999; Johansen et al., 2007; Bünger et al., 2011; Gjerlaug-Enger et al., 2012; Font-i-Furnols et al., 2013; Jay et al., 2013; Judas and Petzet, 2013; Monziols et al., 2013). There is, however, for in vivo studies, some overlap between fat and mammary tissue or fat and lung tissue on one side of the HU scale, and bone or muscle, as well as internal organs such as liver, tumor tissue and blood on the upper side of the HU scale. It has to be considered, additionally, that differences in $\mathrm{CT}$ protocols may lead to variations of up to $20 \%$ in the $\mathrm{HU}$ values, especially for (bone containing) tissues with densities $>1.1 \mathrm{~g} / \mathrm{cm}^{3}$ (Zurl et al., 2014). As described above, tissue segmentation, for example, by threshold setting is based on assumptions of specific mass attenuation coefficients for different body or carcass tissues, which are calculated as HU. It is, however, not always given - not alone depending on the tissue temperature (Szabó and Babinszky, 2008) - that muscle tissue is detected automatically as muscle tissue (or meat $\neq$ meat, fat $\neq$ fat) when comparing different CT machines using the same individual(s) (Bünger et al., 2011). Besides small variations for non-adipose tissue ( $\mathrm{HU}=+49$ to +52 ), there is variation in $\mathrm{CT}$ values or $\mathrm{HU}$ of the adipose tissue within growing pigs. The mean adipose tissue HUs for all pigs $(n=9)$ in a study by McEvoy et al. (2008) were $-90,-98$ and -101 at mean BWs of $51.4,93.8$ and $124.1 \mathrm{~kg}$, respectively. Owing to the anatomical structure of farm animals (or fish: Nanton et al., 2007; Kolstad et al., 2008), however, CT, like DXA, is very well-suited for the discrimination between bone and soft tissues in sheep, chicken, rabbits, beef including buffalo and goose liver in vivo (sheep: Johansen et al., 2007; Kvame and Vangen, 2007; Navajas et al., 2007; Macfarlane et al., 2009; Bünger et al., 2011; Ho et al., 2013; chicken: Milisits et al., 2013; Szentirmai et al., 2013; rabbits: Nagy et al., 2010; beef: Hollo et al., 2008; Navajas et al., 2010; buffalo carcass: Holló et al., 2014; goose liver in vivo: Locsmandi et al., 2005). Milisits et al. (2013) and Szentirmai et al. (2013), for example, provided a so-called fat index for determining the body fat content in broiler chicken and laying hens, respectively, by calculating the ratio of the number of fat pixels within the $\mathrm{HU}$ range from -20 to -200 to the total number of pixels with $\mathrm{HU}$ values for muscle, water and fat between -200 and +200 . The muscle index provided additionally by Milisits et al. (2013) uses the number of muscle pixels within the $\mathrm{HU}$ range from +20 to +200 , instead of the fat pixel $\mathrm{HU}$ range. The variation found by Chang et al. (2011) for various points of visceral and subcutaneous fat in minipigs lies in the range of the abovedefined HU threshold values for 'chicken' fat $(-20$ and -200 ), with $-108.80 \pm 5.77$ as the lowest mean value ( \pm s.d.) for subcutaneous fat and with $-119.41 \pm 6.90$ as the highest HU value for visceral fat. Johansen et al. (2007) provided the following $\mathrm{HU}$ thresholds for tissue segmentation in lambs: bone $v$. soft tissue ' $\mathrm{kC}$ ' $=296$; soft tissue $v$. background noise (air) ' $\mathrm{kA}$ ' $=-156$ and fat $v$. muscle ' $\mathrm{kB}$ ' $=10$. The sum of pixels within these thresholds served as estimates of fat and muscle tissue, although according to the thresholds mentioned water was included into the fat tissue.

The latest machines are now the so-called multi-slice spiral (or helical) CTs based on a rotating X-ray source and an array of X-ray photon sensors on the opposite side of the CT gantry (Ulzheimer and Flohr, 2009). Especially for CT, the development of technology occurs at a breathtaking speed. It took only about 10 years from single-slice to multi-slice machines to be developed (Kopp et al., 2000), with now more than 100 slices for one rotation. The body region covered increased from about $1 \mathrm{~cm}$ to more than $10 \mathrm{~cm} / \mathrm{s}$, whereas the minimal slice thickness decreased from $5 \mathrm{~mm}$ to $<0.5 \mathrm{~mm}$ at the same time (Kalender, 2006). In addition, the gantry size now reaches up to $90 \mathrm{~cm}$ providing space for bigger (heavier) farm animals.

After semi-automatic image analysis using OsiriX (Rosset et al., 2004) or ATAR (Animal Tomogram Analysis Routines) software (Haynes et al., 2010; Bünger et al., 2011; Jay et al., 2013), fat, muscle and bone areas can be calculated within the slices of interest. The traits (phenotypes) calculated serve as the basis for the prediction of carcass and tissue weights or volumes and proportions of muscle, fat and bone in combination with additional linear measurements for 2D gigot muscularity, loin eye muscle area and 2D loin eye muscularity and finally as basis for breeding value estimation (Bünger et al., 2011). Present developments aim at whole-body spiral scanning in order to measure the above traits instead of having to predict them, leading additionally to $3 \mathrm{D}$ gigot muscularity and 3D loin eye muscularity. The 3D information can even help to include the retailer into the development of new products by applying 'PorkCAD', a new 'design butcher' (Virtual Slaughterhouse) system based on a virtual pig created from CT scanning as suggested by Laursen et al. (2013).

Somewhat different approaches and assumptions among the European colleagues from Denmark, France, Hungaria, Ireland, Norway, Sweden, Spain and United Kingdom led to different solutions for carcass grading, and especially formulas for the prediction of the lean meat percentage, which is or should be the basis for the payment of producers (Szabó and Babinszky, 2009). There is, for example, a discussion going on whether meat yield should be determined on the 
basis of scale weight or on the basis of $\mathrm{CT}$ volume (Olsen and Christensen, 2013 v. Daumas et al., 2013). Scale weight would require assumptions or knowledge about the 'true' CT density of lean meat (Daumas et al., 2013). Differences in the calculation of CT densities for lean meat result in different lean meat weights for similar lean meat volumes, making the harmonization among different countries or among various CT scanners more complicated (Daumas et al., 2013; Olsen and Christensen, 2013).

Correspondingly, CT studies post mortem are also aiming to determine the salt content in the dry-cured ham, because the changing $\mathrm{NaCl}$ and $\mathrm{H}_{2} \mathrm{O}$ proportions lead to modified X-ray attenuations (Fulladosa et al., 2010); whereas Frisullo et al. (2010) used micro-CT for the rapid estimation of intramuscular fat (IMF) in beef and for the description of the fat microstructure. Anton et al. (2013) compared chemical analysis or dissection with $\mathrm{CT}$ in order to determine the IMF and carcass fat content of beef in a study focusing on the thyroglobulin (TG) polymorphism. They calculated correlations between IMF (\% from Soxhlet analysis) and CT fat (\%) in musculus longissimus dorsi, and between dissected fat (\%) of the right carcass-half and CT fat (\%) between the $11^{\text {th }}$ and $13^{\text {th }}$ rib joint of 0.71 and $0.96(P<0.001)$, respectively. In this context, Jose et al. (2009) stated that CT scanning does not negatively affect the quality of (beef or lamb) meat, especially in terms of color. Kongsro and Gjerlaug-Enger (2013) - in pigs - and Clelland et al. (2013) - in sheep started using CT for the measurement of meat quality (IMF content) in vivo. The regression coefficients between CT IMF in vivo (+ further variables) and IMF in the carcass loin eye reached values of adjusted $R^{2} \leqslant 0.71$ (r.m.s.e. $\geqslant 0.36$ ) for Texel lambs, whereas a significantly lower relationship between IMF and CT intensity values was found $\left(R^{2}=0.18\right.$; RMSEP $=0.48)$ according to Kongsro and Gjerlaug-Enger (2013) in pigs. In contrast to the US study by Jiao et al. (2014), the relatively low level of IMF and small variation in the Duroc boars studied in comparison with ordinary slaughtered pigs may have led to low prediction accuracies based on CT signal intensities. Font-i-Furnols et al. (2013) describe a further method to determine IMF in pork loins using CT. The best prediction of IMF resulted from ordinary linear regression analysis when data from two tomograms were used $\left(R^{2}=0.83\right.$ and RMSEPCV $\left.=0.46 \%\right)$. However, genomic selection for IMF improvement based on NIR derived IMF might be a more promising approach according to Gjerlaug-Enger et al. (2014).

Deeper insights into the physiological role of IMF in comparison with intermuscular fat (adipose tissue) are provided by Hausman et al. (2014).

\section{MRI}

The principle of MRI relies on the net magnetization of spinning nuclei with uneven proton and neutron numbers and RF-induced 3D-coded voltage readings with tissuespecific relaxation times depending on spin-lattice (T1) and spin-spin (T2) interactions combined with the proton density (Laurent et al., 2000; Baulain and Henning, 2001;
Mitchell et al., 2001). In addition, T1 and T2 depend on the magnetic field strength (Kato et al., 2005). Furthermore, the effect of dehydration plays a crucial role not alone in (dry) cured ham and can be used for MRI applications by taking advantage of changing $\mathrm{T} 1$ and $\mathrm{T} 2$ relaxation times, which depend on the salt content in the ham (Fantazzini et al., 2009).

A combination of magnetic field produced either by a ferromagnetic, electromagnetic or superconducting system with a field strength between 0.1 and $7 \mathrm{~T}$ and so-called gradient coils with a corresponding RF frequency (Larmor frequency) sequence creates a number of cross-sectional images with a 3D voxel definition for the $x-, y$ - and $z$-axis direction. A Fourier transformation helps in recalculating the signal information from the spectral domain into pixel (or voxel)-wise signal intensity values in a 'gray scale domain' visible on the 'computer' screen. For a T1-weighted sequence with a TR (time between two consecutive RF pulse signals or between successive excitations) of $300 \mathrm{~ms}$ and a TE (time between echoes $=$ between middle of exciting RF pulse signal and middle of spin echo production) of $17 \mathrm{~ms}$, the fat tissue containing pixels have rather high signal intensities, whereas the non-fat pixels show lower signal intensities. This pattern, however, changes on chilled objects (Monziols et al., 2005 and 2006). As shown in Figure 2, a T1-weighted sequence would show dark pixels (low signal intensity) for fat tissue and brighter pixels for lean meat tissue (relatively higher signal intensity).

The above-mentioned Larmor (resonance) frequency differs depending on the isotope of interest and the magnetic field strength. Because the isotope ${ }^{1} \mathrm{H}$ has the largest relative sensitivity and highest natural frequency compared with ${ }^{2} \mathrm{H}$ and ${ }^{3} \mathrm{H}$, proton or ${ }^{1} \mathrm{H}$ nuclear MRI is the most often used method, and is even applied for the study of pork pie (Gaunt et al., 2013).

Usually, an MRI or also a CT (DECT) scan starts with a socalled scout or localizer image sequence in order to be able to define the 'slice' positions and directions as targeted. After successful image acquisition and data storage, a quantitative image analysis is required in order to measure - either in the most simple way - the regions of interest (distances or areas) or calculate - after a more challenging segmentation procedure - the volumes of interest relevant for body or carcass composition measurements. Based on T1 mapping, Kullberg et al. (2006 and 2007), for example, described a fully automated protocol for MR image analysis, focusing on the segmentation of visceral and subcutaneous fat in humans, whereas Addeman et al. (2015) suggested a so-called fat fraction mapping for the automatic determination of subcutaneous adipose and intra-abdominal adipose tissue within the total adipose tissue.

Various free or commercial software packages are available in order to automate image segmentation into muscle/ lean meat, fat, bone and, if necessary, gastrointestinal tract/ abdominal content (Figure 3). This procedure can be standardized more easily for CT images than for MRI images, because of the 'unique' application of HU for tissues like 


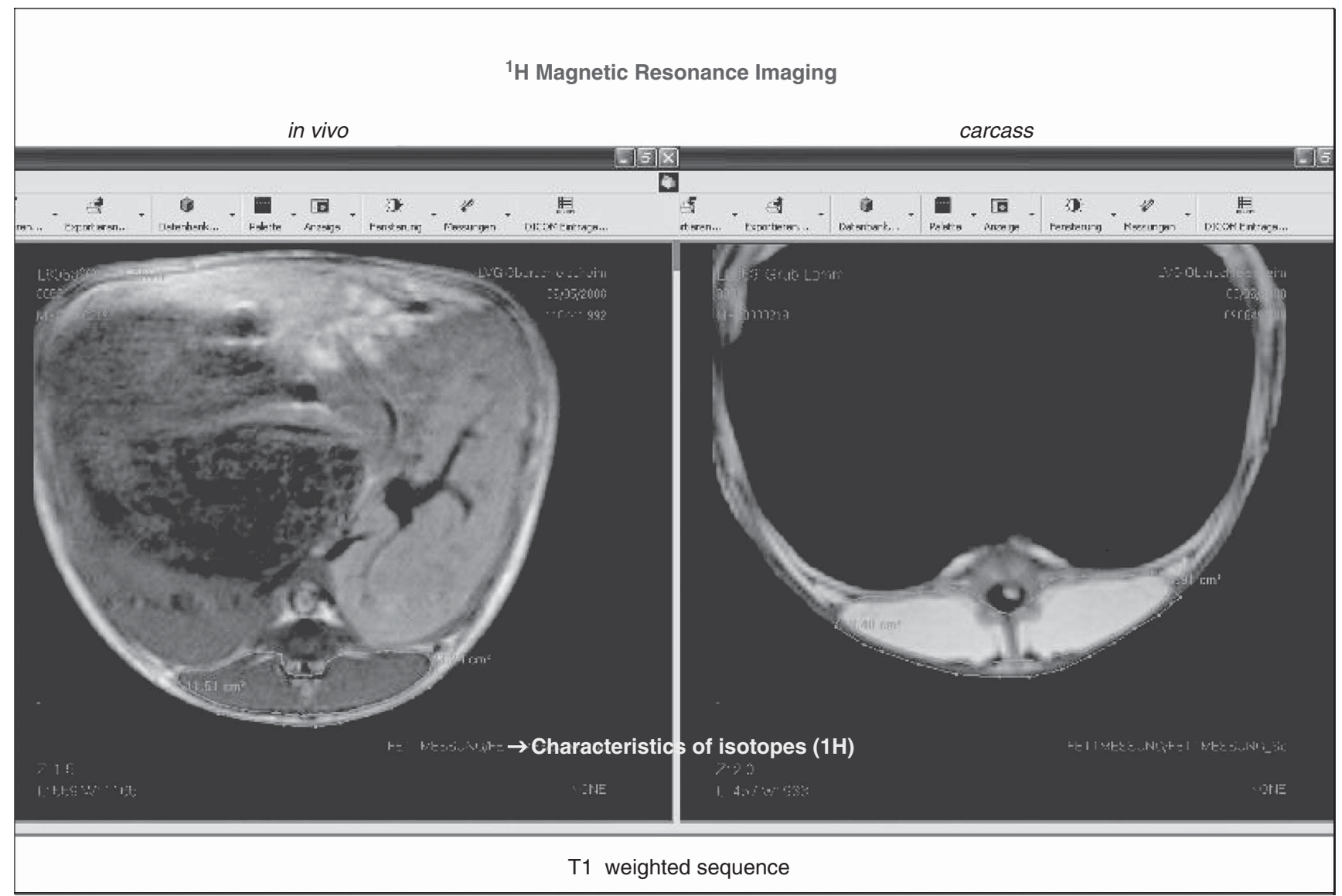

Figure 2 Differences in NMR proton characteristics depending on body temperature (left: lamb in vivo $\sim 37^{\circ} \mathrm{C}$, right: lamb carcass chilled $<8^{\circ} \mathrm{C}$, free software DicomWorks, ${ }^{\circ}$ Philippe PUECH).

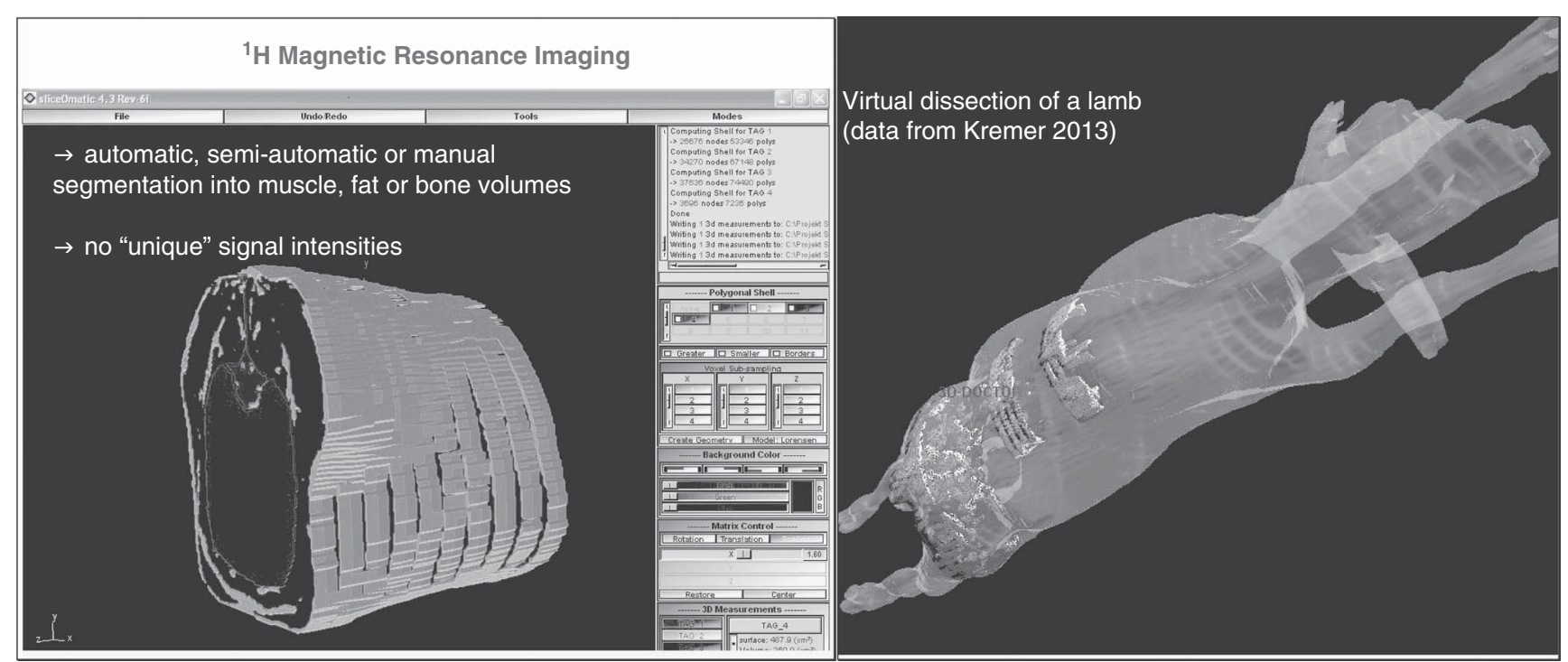

Figure 3 Examples for image analysis and 3D re-calculation (left software used: sliceOmatic, Tomovision Inc.; right software used: 3D DOCTOR, Able Inc., data from Kremer, 2013).

bone, muscle (water) and fat. Signals within MR images depend on the tissue-specific relaxation times $\mathrm{T} 1$ and $\mathrm{T} 2$, including proton density, and on various technical conditions and sequence settings such as the magnetic field strength, the RF pulse sequence(s), slice thickness, distance between slices, number of acquisitions and the specification of (body) coil used.

A relatively new non-invasive (but non-imaging) method 'QMR' - quantitative magnetic resonance - is still in the evaluation phase for farm animals (Mitchell et al., 2012). 


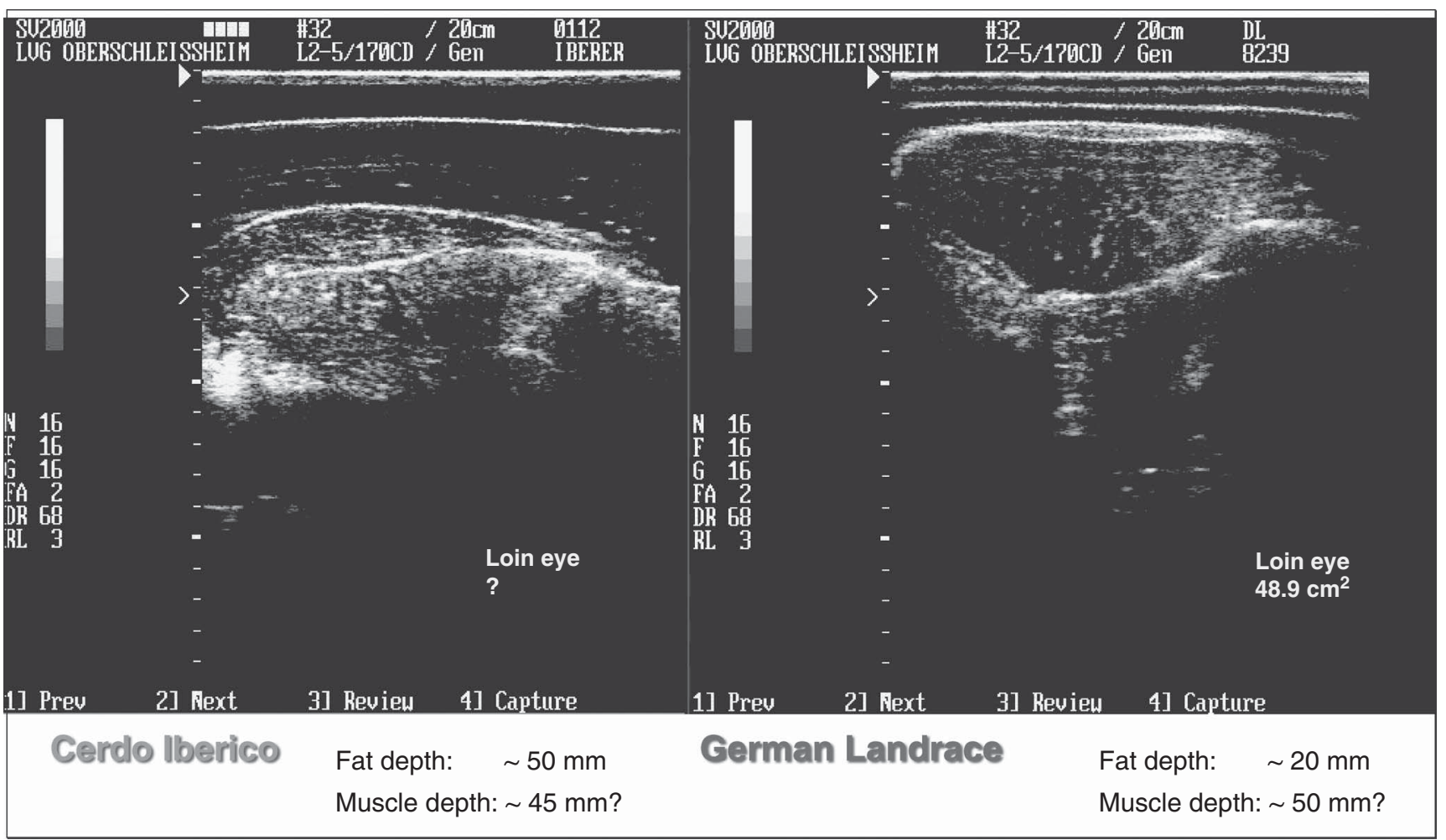

Figure 4 Comparison of 'obese' and 'standard' pigs (using a variable 2.5 to $5 \mathrm{MHz}$ 'backfat' 17-cm transducer).

\section{US scanning/imaging}

Information retrieval by measuring the velocity of sound is the only method among the methods described in this study that depends on mechanical energy fluctuations. The general principle is based on the partial reflection of (Iongitudinal) US waves from the interface between different media and/or body tissues ( $>20 \mathrm{kHz}$, Scholz and Baulain, 2009; Halliwell, 2010; Scholz and Mitchell, 2010; Pathak et al., 2011).

Different tissues have different (sound) attenuation coefficients depending on the frequency for the creation of the US (waves), whereas the speed of longitudinal sound waves increases with the density of the material the sound wave is travelling through (Halliwell, 2010; Culjat et al., 2012). Because the density of (body) tissues is also temperaturedependent, it makes a difference if a (chilled) carcass or a living animal is 'ultrasonographed'. The speed of US is $1403 \mathrm{~m} / \mathrm{s}$ in water of a temperature of $0^{\circ} \mathrm{C}$ and $1472 \mathrm{~m} / \mathrm{s}$ in water of a temperature of $17^{\circ} \mathrm{C}$ (Vogt et al., 2008). Van de Sompel et al. (2012) obtained a calculated speed of US of $1524 \mathrm{~m} / \mathrm{s}$ in water with a temperature of $37^{\circ} \mathrm{C}$ for a salinity of $0 \%$ at 0 meter below water.

Because of the accelerated technical improvement of real-time linear-phased array ultrasonic transducers and scanners, this technique has become the most common technology for (farm) animal body and carcass composition assessment (Starck et al., 2001; Mitchell and Scholz, 2009, Scholz and Baulain, 2009).

Two-dimensional US images from so-called B-mode (brightness) devices provide information about adipose tissue depots and cross-sectional areas of muscles, whereas
A-mode devices (amplitude) can be used for simple distance measurements of fat or muscle (meat) layers. Real-time B-mode information (2D or 3D images) result from rapid electronic switching or phased array transducers (a number of piezoelectric elements) of different shapes (Starck et al., 2001). At present, most of the US devices for performance testing use (linear) phased array transducers to convert electronic energy to high-frequency ultrasonic (mechanical) energy that travels through the animal body in short pulses. As soon as ultrasonic waves meet at an interface between two tissues that differ in acoustical properties, a part of the (longitudinal) ultrasonic waves are reflected back to the receiver probe (the phased array transducer). Variations in fat, muscle or bone tissue depths or in the distribution of, for example, intermuscular and especially IMF result in time differences in reflected ultrasonic wave signals affected additionally by absorption and refraction (scatter) of the mechanical energy (Starck et al., 2001). These effects combined with variations caused by the expertise of the testing person, age/weight of the animal and the behavior of the animal tested lead in some cases to a challenging interpretation of the US imaging or scanning results, as can be seen from Figure 4. They make the measurement of areas or even volumes (weights) less accurate in comparison with MRI or CT. Depending on the transducer and on the scan settings in terms of frequency, it might be the case that the measurement of, for example, the loin eye area becomes almost impossible and requires a lot of educated 'anatomical' guessing in order to provide reasonable data (Figure 4). Related to the above measurement site on the (beef) animal, 
Scholz, Bünger, Kongsro, Baulain and Mitchell

Table 3 Examples of heritability estimates $\left(\mathrm{h}^{2}\right.$, s.e.) for intramuscular fat determined by US in vivo

\begin{tabular}{llllll}
\hline \hline Non-invasive Trait & Technique & Species & Breed & $h^{2}$ (s.e.) & Reference \\
\hline Intramuscular fat (\%) & \multirow{2}{*}{ US } & Cattle & Angus & $0.12(0.03)$ & Ravagnolo et al. (2010) \\
& & Angus-Brahman & $0.78(0.09)$ & Elzo et al. (2010) \\
& & Diverse & $0.12-0.88$ & Suther (2009) \\
& & Pig & Duroc & $0.54(0.11)$ & Jiao et al. (2014) \\
\hline \hline
\end{tabular}

US = ultrasound imaging.

${ }^{1}$ References before 2010 in Supplementary Material S1.

Harangi (2013) stated for Charolais bulls that the relationship between ultrasound rib eye area (UREA) and 'planimeter' carcass rib eye area (CREA) was higher when measured between the $12^{\text {th }}$ and $13^{\text {th }}$ rib instead of between the $11^{\text {th }}$ and $12^{\text {th }}$ rib with $R^{2}$ of 0.91 and 0.84 (CV 2.16\% v. $5.3 \%$ ), respectively. Török et al. (2009) found slightly modified relationships between UREA and CREA for four different beef breeds (Limousin $R^{2}=0.92$, Charolais $R^{2}=0.64$, Angus and Simmental $R^{2}=0.55$ ).

It must always be considered that the attenuation of ultrasonic energy increases with a rising frequency, whereas the tissue penetration depth of the ultrasonic energy waves decreases with increasing attenuation. Therefore, probes with a frequency between 2 and $5 \mathrm{MHz}$ will be used for measurements, including muscle depth or muscle area (volume), whereas probes with frequency $>5 \mathrm{MHz}$ (up to 7.5 MHz) will be used for 'subcutaneous' scanning where deeper muscle regions are not of interest (Schröder and Staufenbiel, 2006; Pillen and van Alfen, 2011).

As muscle tissue has a higher US attenuation than fat tissue, US technology is widely used in farm animal performance testing (Stouffer, 2004; Pathak et al., 2011; Ayuso et al., 2013), obesity diagnostics (Barbero et al., 2013), body condition scoring (Schröder and Staufenbiel, 2006) or for carcass grading (Branscheid et al., 2011).

\section{Application in existing breeding programs}

The above-mentioned practical applications of US measurements of live animals and carcasses are being extended to genetic selection programs (Müller and Polten, 2004; Kleczek et al., 2009; Emenheiser et al., 2010; Case et al., 2012; Maximini et al., 2012; Harangi, 2013), by including in vivo IMF (uIMF) measurements in Duroc pigs (Maignel et al., 2010), and, for example, in Angus cattle (Ravagnolo et al., 2010), Nelore cattle (Bonin et al., 2010) or Angus-Brahman crossbred cattle (Elzo et al., 2010).

As '...heritability is a simple dimension less measure of the importance of genetic factors in explaining the differences between individuals, and it allows an immediate comparison of the same trait across populations and of different traits within a population' (Visscher et al., 2008), we use that (additive) genetic variance indicator in the following comparisons of different traits derived from non-invasive techniques (Tables 3 and 4). Heritability estimates for uIMF were rather low with $h^{2}=0.12$ for Angus in Urugay
(Ravagnolo et al., 2010) in contrast with very high (most likely overestimated) $h^{2}$ of 0.78 for a very variable AngusBrahman population in Florida (Elzo et al., 2010). Suther (2009) summarizes a number of earlier studies and shows a similar range of heritability estimates for marbling (IMF) in beef cattle (Table 3).

Expectedly, real-time US data of muscle depth in sheep or breast muscle thickness in broilers showed medium-to-high direct heritability estimates between 0.2 and 0.51 (Jones et al., 2004, Wolf and Jones, 2007; Grosso et al., 2010, Maximini et al., 2012; Table 4), whereas heritability estimates - depending on age - varied in a similar range between 0.31 and 0.42 for loin muscle (or rib eye) area (between $12^{\text {th }}$ and $13^{\text {th }}$ ribs) in Bos indicus (Bonin et al., 2010; Pinheiro et al., 2011), Angus-Brahman (Elzo et al., 2010) and multi-breed beef cattle (Jeyaruban and Johnston, 2014). Heritability estimates for back fat thickness (between $12^{\text {th }}$ and $13^{\text {th }}$ ribs) showed slightly lower values ranging from 0.06 to 0.32 (Bonin et al., 2010; Elzo et al., 2010; Pinheiro et al., 2011) as well as for rump fat thickness with values from 0.26 to 0.29 (alone Pinheiro et al., 2011). The advantage of US scanning can be concluded from the above references. US is the only method among the reviewed ones that can be applied in (beef) cattle (Drennan et al., 2009) without size restrictions as there exist for CT, DXA and MRI.

Besides US, CT alone is being used in practical farm animal breeding programs, especially for the selection of body composition traits in pigs and sheep. In this context, CT is, meanwhile, declared as 'part of the routine genetic selection programs in modern times' (Ley, 2013). This, however, is true for only a very few breeding organizations or CT service (research) units in the world so far - such as, for example, for sheep selection in Australia, New Zealand and United Kingdom (e.g. Lambe et al., 2008; Arthur et al., 2011, Bünger et al., 2011) or pig (and sheep) selection in Norway (e.g. Kvame et al., 2006; Kongsro et al., 2008; Gjerlaug-Enger et al., 2012). GjerlaugEnger et al. 2012 estimated heritabilities for CT lean meat percentage (LMP) between 0.5 and 0.57 (Table 4).

Therefore, the available high additive genetic variance for lean meat percentage in both Norwegian pig breeds based on in vivo whole-body CT measurement makes that technique very efficient for selection decisions without having to sacrifice potential breeding animals. At present, the capacity of modern CT machines allows the acquisition of more than 1100 slices per farm animal (e.g. male or female breeding pigs) in an actual whole-body scanning time of less than a 
DXA, CT, MRI and US in farm animals

Table 4 Examples of heritability estimates $\left(\mathrm{h}^{2}\right.$, s.e.) for body composition traits determined by DXA, CT or US

\begin{tabular}{|c|c|c|c|c|c|}
\hline Non-invasive trait & Technique & Species & Breed & $h^{2}$ (s.e.) & Reference \\
\hline \multirow[t]{2}{*}{ Lean meat (\%) } & \multirow[t]{2}{*}{$\mathrm{CT}$} & \multirow[t]{2}{*}{ Pig } & Duroc & $0.57(0.05)$ & \multirow[t]{2}{*}{ Gjerlaug-Enger et al., 2012} \\
\hline & & & Landrace & $0.50(0.05)$ & \\
\hline Fat $(\%)$ & DXA & Pig & F2 with Göttinger Minipig & $0.57(0.14)$ & Kogelman et al., 2013 \\
\hline \multirow{4}{*}{ Lean Meat $(\mathrm{g})$} & \multirow{3}{*}{$\mathrm{CT}$} & \multirow[t]{3}{*}{ Sheep } & Charolais, Suffolk, Texel & $0.47,0.45,0.46(0.09)$ & Jones et al. $(2004)^{2}$ \\
\hline & & & Norwegian White & $0.57(0.16)$ & Kvame and Vangen (2007) \\
\hline & & & Scottish Blackface & $0.48(0.17)$ & Karamichou et al. (2006) \\
\hline & DXA & Pig & F2 with Göttinger Minipig & $0.71(0.14)$ & Kogelman et al. (2013) \\
\hline \multirow[t]{4}{*}{ Fat $(g)$} & \multirow[t]{3}{*}{$\mathrm{CT}$} & \multirow{3}{*}{ Sheep } & Charolais Suffolk, Texel & $0.38,0.41,0.40(0.09)$ & Jones et al. (2004) \\
\hline & & & Norwegian White & $0.29(0.13)$ & Kvame and Vangen (2007) \\
\hline & & & Scottish Blackface & $0.6(0.28)$ & Karamichou et al. (2006) \\
\hline & DXA & Pig & F2 with Göttinger Minipig & $0.43(0.13)$ & Kogelman et al. (2013) \\
\hline Bone mineral (g) & DXA & Pig & F2 with Göttinger Minipig & $0.76(0.15)$ & Kogelman et al. (2013) \\
\hline \multirow[t]{2}{*}{ Bone mass $(\mathrm{g})$} & \multirow[t]{2}{*}{$\mathrm{CT}$} & \multirow[t]{2}{*}{ Sheep } & Norwegian White & $0.51(0.15)$ & Kvame and Vangen (2007) \\
\hline & & & Scottish Blackface & $0.14(0.11)$ & Karamichou et al. (2006) \\
\hline Bone mineral density $\left(\mathrm{g} / \mathrm{cm}^{2}\right)$ & DXA & Pig & F2 with Göttinger Minipig & $0.92(0.16)$ & Kogelman et al. (2013) \\
\hline \multirow[t]{5}{*}{ Loin eye area $\left(\mathrm{cm}^{2}\right)$} & \multirow[t]{2}{*}{$\mathrm{CT}$} & \multirow[t]{2}{*}{ Sheep } & Scottish Blackface & $0.33(0.12)$ & Karamichou et al. (2006) \\
\hline & & & Five diverse Austrian & $0.24(0.03)$ & Maximini et al. (2012) \\
\hline & \multirow[t]{3}{*}{ US } & \multirow[t]{2}{*}{ Cattle } & Nellore & 0.31 to $0.34(0.03)$ & Caetano et al. (2013) \\
\hline & & & Hanwoo & 0.09 to 0.24 (0.09 to 0.16$)$ & Lee et al. (2014) \\
\hline & & Pig & Duroc, Landrace, Yorkshire & 0.21 to $0.22(<0.01)$ & Choi et al. (2013) \\
\hline \multirow[t]{2}{*}{ Fat area $\left(\mathrm{cm}^{2}\right)$} & \multirow[t]{2}{*}{ CT } & \multirow[t]{2}{*}{ Sheep } & Scottish Blackface & 0.5 to 0.76 (0.08 to 0.22$)$ & Karamichou et al. (2006) \\
\hline & & & five diverse Austrian & 0.36 to $0.4(0.03)$ & Maximini et al.( 2012) \\
\hline \multirow[t]{5}{*}{ Muscle depth (mm, cm) } & \multirow[t]{5}{*}{ US } & \multirow[t]{4}{*}{ Sheep } & Charolais Suffolk, Texel & $0.30,0.32,0.29(0.01$ to 0.02$)$ & Jones et al., 2004 \\
\hline & & & Norwegian White & $0.28(0.05)$ & Kvame \& Vangen, 2007 \\
\hline & & & five diverse Austrian & $0.28(0.05)$ & Maximini et al. (2012) \\
\hline & & & Broiler commercial line & 0.28 to $0.51(0.02)$ & de Genova Gaya (2013) \\
\hline & & Pig & Duroc & $0.39(0.09)$ & Jiao et al. (2014) \\
\hline \multirow[t]{8}{*}{ Fat depth $(\mathrm{mm}, \mathrm{cm})$} & \multirow[t]{8}{*}{ US } & \multirow[t]{3}{*}{ Sheep } & Charolais, Suffolk, Texel & $0.34,0.35,0.38(0.01$ to 0.02$)$ & Jones et al. (2004) \\
\hline & & & Norwegian White & $0.44(0.06)$ & Kvame and Vangen (2007) \\
\hline & & & five diverse Austrian & $0.29(0.05)$ & Maximini et al. (2012) \\
\hline & & \multirow[t]{3}{*}{ Cattle } & Angus & 0.26 to 0.46 (0.03 to 0.08$)$ & MacNeil and Northcutt (2008) \\
\hline & & & Nellore & $0.23(0.02)$ & Caetano et al. (2013) \\
\hline & & & Hanwoo & 0.05 to 0.47 (0.06 to 0.15$)$ & Lee et al. (2014) \\
\hline & & Pig & Duroc & $0.58(0.09)$ & Jiao et al. (2014) \\
\hline & & & Duroc, Landrace, Yorkshire & $0.32,0.41,0.38(<0.01)$ & Choi et al. (2013) \\
\hline
\end{tabular}

CT = computed tomography; DXA = dual-energy X-ray absorptiometry; US = ultrasound.

${ }^{1}$ Many more studies with 'US' heritability estimates exist.

${ }^{2}$ References before 2010 in Supplementary Material S1.

minute in vivo (Gjerlaug-Enger et al., 2012). Handling, scanning and image analysis for one potential breeding boar or gilt under performance testing takes, in the meantime, only about $15 \mathrm{~min}$. Image analysis is fully automated using MatLab $^{\circledR}$ (The MathWorks Inc., Natick, MA, USA) procedures, especially adapted to CT volume information. A total of 24 boars tested per day is a routine application at TopigsNorsvin facilities. Information from 1100 slices per potential breeding boar are processed for the body composition phenotypes like lean meat $(\mathrm{kg}, \%)$, fat $(\mathrm{kg}, \%)$, bone $(\mathrm{kg}, \%)$, primal cuts $(\mathrm{kg})$, live and 'carcass' weight $(\mathrm{kg})$, as well as carcass yield (\%) (Gjerlaug-Enger et al., 2012).

Slightly modified approaches serve for sheep selection programs at the SRUC (Scotland, UK) in Edinburgh. Routine application at the SRUC covers three important body regions such as thorax (transversal slice at thoracic vertebra 8), loin (lumbar vertebra 5) and gigot (ischium - back of the pelvis) of breeding sheep (Bünger et al., 2011).

Maximini et al. (2012) compared genetic (across breeds) parameters for phenotypes derived from either CT or US in five Austrian sheep breeds. They found moderate $h^{2}$ estimates for US scan traits for eye muscle depth (0.28) and for fat depth (0.29), whereas CT traits showed higher (across breed) $h^{2}$ estimates for fat $(0.36$ and 0.40$)$, but not for the eye muscle area (0.24) (Table 4). Among other unknown reasons, these slightly problematic across-breed heritability estimates (Visscher et al., 2008) led Austrian sheep breeders to abandon CT in favor for US (Fürst-Waltl and Grill, 2013).

In contrast with Maximini et al. (2012), Karamichou et al. (2006) found, for all CT tissue areas, moderate-to-high heritability estimates between 0.23 and 0.76 . The heritability estimates for CT fat areas started at 0.5 , whereas the 
estimates for loin eye muscle area showed an average value of 0.33 for the univariate model (Table 4). Meanwhile, sheep breeders from New Zealand advocated the combination of US and CT in a stage breeding design because 'selection of meat sheep on CT measurements will increase genetic progress, compared with selection on US measurements alone' (Bünger et al., 2011). In this context, Moore et al. (2011) demonstrated that, for sheep, combining CT with US scanning would increase the estimated breeding value (EBV) accuracy by $6 \%$ to $20 \%$ in comparison with US scanning alone, thus supporting the great benefit of CT. These calculations are derived from US prediction accuracies $\left(R^{2}\right)$ in the order of 0.65 and 0.50 for fat $(\mathrm{kg})$ and muscle $(\mathrm{kg})$, respectively, with heritabilities for US-measured muscle and fat depth of 0.24 to 0.32 and 0.19 to 0.38 , respectively (Jones et al., 2004; Bünger et al., 2011; Mortimer et al., 2014), whereas accuracies of CT-based predictions in meat sheep for fat and muscle weight are significantly higher with $R^{2}=0.99$ (r.s.d. $=434 \mathrm{~g}$ ) and 0.97 (r.s.d. $=611 \mathrm{~g}$ ), respectively, combined with expected corresponding heritabilities between 0.4 and 0.5 (Young et al., 2001) or between 0.35 and 0.45 (Jones et al., 2004).

Neither DXA nor MRI are being actively used in commercial breeding programs so far, although Kogelman et al. (2013) estimated 'heritability' estimates in a F2 pig population originating from crosses of Duroc or Yorkshire and Göttinger Minipig. The heritability estimate for DXA lean mass, of 0.71 , is higher than that for DXA fat mass, of 0.43 . This observation corresponds with the order of the sheep CT heritability estimates for lean and fat mass, with the exception of $h^{2}$ estimates for the Scottish Blackface (Table 4).

\section{Harmonization and comparison of techniques}

Reference (volume) phantoms could help making different CT machines comparable (Christensen and Angel, 2013). The same is true for DXA, because different machines within or among different manufacturers use various settings in order to measure the $\mathrm{X}$-ray attenuation coefficient ( $R$ value) based on the specific X-ray attenuation of body tissues for highand low-energy levels (Wood, 2004; Plank, 2005; Lösel et al., 2010). It is even more difficult with MRI, because there are no standardized signal intensities describing one or the other tissue (Baulain and Henning, 2001; Mitchell et al., 2001; Kremer et al., 2012 and 2013; Collewet et al., 2013; Addeman et al., 2015; Pérez-Palacios et al., 2014). In addition, not only the velocity of sound depends on the surrounding temperature of body/carcass tissues but also the attenuation of X-rays (Szabó and Babinszky, 2008), and the electromagnetic patterns of protons lead to different results for in vivo and postmortem (carcass) measurements within the same animal.

The objective of all imaging techniques is to achieve an optimum signal-to-noise ratio combined with small voxel sizes for discrete image segmentation into the body tissues (structures) of interest (Hanna and Cuschieri, 2001). Chemical shift or partial volume effects must be considered when interpreting the accuracy of MRI-derived body/carcass composition estimates (Monziols et al., 2005). Monziols et al. (2006) found an increase in estimation accuracy (higher $R^{2}$, lower residual standard deviation) for muscle or fat weight and percentage with an increase in body regions (slices) analyzed. If the most relevant body regions are accounted for, or even the whole body, according to the Cavaleri method, MRI, like CT (and DXA), is a very useful tool for growth- or obesity-related studies, because there is no need for serial slaughter anymore (Cavaleri method: Gong et al., 2000; Glasbey and Robinson, 2002; Baulain et al., 2003; Mandarim-De-Lacerda, 2003; Vogt et al., 2007; Szabó and Babinsky, 2009; Arthur et al., 2011).

Only a very few studies exist where DXA measurements are being compared with MRI (Vogt et al., 2007; Brandberg, 2009; Bernau et al., 2015). Vogt et al. (2007) found a relationship of $R^{2}=0.95$ between whole-body fat measurements performed by DXA (pencil-beam scanner) and by MRI (1.5 T) in human probands, whereas DXA (GE Lunar DPX-L) underestimated the total fat weights compared with both CT $-5.23 \mathrm{~kg}(1.71 \mathrm{~kg})$ and MRI $-4.67 \mathrm{~kg}$ $(2.38 \mathrm{~kg})$ in another study on human probands, summarized in the thesis by Brandberg (2009). Bernau et al. (2015) showed for 20 intact boars that both, MRI and DXA, can be used with high accuracy $\left(R^{2}=0.88\right.$ or 0.91 , r.m.s.e. $=0.9 \%$ or $0.82 \%$, respectively) to predict lean meat percentage from dissection. The combination of both techniques resulted in an $R^{2}$ of 0.95 (with r.m.s.e. $=0.61 \%$ ). Mitchell and Scholz (2009) could additionally show that the relationship between DXA measurements and the corresponding reference carcass traits was higher than the relationship between US measurements and the same corresponding reference carcass traits with a correlation of $r=-0.85(-0.87)$ for DXA lean $\% v$. carcass fat $\%$ in comparison with a corresponding relationship for US fat-free mass $\% v$. carcass fat $\%$, with $r=-0.69(-0.74)$ for pigs with a BW of 110 or $100 \mathrm{~kg}$, respectively. These findings were supported by Suster et al. (2004), who reported that DXA measurement values are more closely related with chemically determined carcass values than are carcass P2 back fat measurements performed using a ruler. DXA (or whole-body/carcass MRI/CT) covers the total amount or percentage of body fat or lean meat, whereas US- or ruler-based back fat measurements can only account for subcutaneous fat layers on a limited number of body regions, and therefore cannot account for all the differences in the distribution of fat layers when comparing different farm animal breeds or genotypes, for example.

Table 5 summarizes studies with the 'closest' published relationships between lean meat percentage (LMP) from dissection and the four techniques (DXA, CT, MRI and US) reviewed in this study. All data originate from pigs (carcasses/in vivo) for two reasons. First, pigs still have a relatively high variability in body or carcass composition, especially in the subcutaneous fat layer, and, second, reasonable data for the four techniques in the review exist mainly for pigs, followed by sheep and to some extent by poultry or fish. 
Table 5 Comparison of non-invasive techniques (reference: lean meat \% from dissection)

\begin{tabular}{|c|c|c|c|c|c|c|c|}
\hline \multirow[b]{3}{*}{ Method } & \multirow[b]{3}{*}{ Reference tissue } & \multicolumn{4}{|c|}{ Accuracy (alone for pigs) } & \multirow[b]{3}{*}{ Scan time whole body } & \multirow[b]{3}{*}{ X-radition exposure (mrem) } \\
\hline & & $R^{2}$ & r.m.s.e. & $R^{2}$ & r.m.s.e. & & \\
\hline & & \multicolumn{2}{|c|}{ Carcass } & \multicolumn{2}{|c|}{ In vivo } & & \\
\hline $\mathrm{CT}$ & Lean meat $(\%)$ & $<0.99$ & $>0.54$ & $<0.94$ & $>1.00$ & 5 to $30 \mathrm{~s}$ & 9 to 15 \\
\hline MRI & Lean meat (\%) & $<0.98$ & $>0.62$ & $<0.87$ & $>1.20$ & 15 to $30 \mathrm{~min}$ & None \\
\hline DXA & Lean meat $(\%)$ & $<0.91$ & $>0.82$ & $<0.72$ & $>1.75$ & 7 to $13 \mathrm{~min}$ & 0.03 to 0.06 \\
\hline US & Lean meat (\%) & $<0.77$ & $>0.70$ & $<0.53$ & $>1.95$ & - & None \\
\hline
\end{tabular}

$\mathrm{CT}$ = computed tomography; $\mathrm{MRI}=$ magnetic resonance imaging; $\mathrm{DXA}=$ dual-energy $\mathrm{X}$-ray absorptiometry; US = ultrasound.

Carcass: CT data from Judas et al. (2005), Romvari et al. (2006), Vester-Christensen et al. (2009), Monziols et al. (2013); MRI data from Baulain and Henning (2001), Mitchell et al. (2001), Baulain et al. (2003), Collewet et al. (2005); Monziols et al. (2006); DXA data from Bernau et al. (2015); Dunshea et al. (2007) (ewes and wheters: $\%$ chemical lean: $\left.R^{2}=0.94\right)$; and US data from Branscheid et al. (2011).

In vivo: CT data from Romvari et al. (2005) (no error terms provided); MRI data from Baulain and Henning (2001) $\left(R^{2}=0.91\right.$, r.m.s.e. $=1.90 \%$ in lambs), Mitchell et al. (2001), Scholz (2002); DXA data from Scholz and Förster (2006), Mitchell et al. (2002) (pigs: $R^{2}=0.84$ for chemical lean \%); and US data from Youssao et al. (2002), Doeschl-Wilson et al. (2005).

References before 2010 in Supplementary Material S1.

Table 6 Advantages and disadvantages of non-invasive techniques for the determination of body or carcass composition

\begin{tabular}{lll}
\hline \hline & Advantages & Disadvantages \\
\hline Dual-energy X-ray absorptiometry (DXA) & Easy handling & Alone 2D information (so far) \\
& Low radiation & No direct data for lean meat (in vivo) \\
& Medium price & \\
& Quick data analysis & \\
& Regional data analysis & \\
Computed tomography (CT) & Very high anatomical resolution & X-radiation exposure \\
& High speed & Expensive \\
& Whole-body 3D data & \\
Magnetic resonance imaging (MRI) & Automatic data analysis & \\
& Excellent soft tissue differentiation & Expensive (if high field strength magnet) \\
& Whole-body 3D data & Rather slow (whole body) \\
& Functional imaging & Availability (farm animal sector) \\
Ultrasound imaging (US) & No radiation & \\
& Portable, extensive database for some species & Less accurate anatomical resolution \\
& Reasonably priced & Image analysis not easily automated \\
& No radiation & No whole-body information \\
\hline \hline
\end{tabular}

\section{Conclusion for imaging/non-invasive methods}

If sufficient automatic procedures are available, the 'Cavalieri' method, or even better a whole-body scan, is the preferred CT or MRI imaging procedure, because whole-body information does not require breed, species or age-/weight-specific prediction equations.

For performance testing, a combination of the various methods listed below might be optimal based on cost and accuracy:

(1) If radiation and the high investment price are not an issue, then use a 'New Generation' spiral, multi-slice CT for the measurement of body/carcass composition.

(2) If 3D information (e.g. carcass cuts, muscle or fat volumes) is not required, use DXA.

(3) If radiation is an issue, use MRI. Anesthesia is required in most cases (1-3)!
(4) If a 'quick' and 'easy' answer is the objective, use A-mode US and for little more B-mode. In all cases (1-4), a scale is very useful!

According to Kallweit (1992), one could still conclude that 'There are advantages and disadvantages of individual systems in their present state...' as summarized in Table 6. '... The rapid progress in technical development may lead to further improvements in the future.' Actually, nothing has changed in the past 20 years .

Present and potential future applications - non-invasive measurements of new exactly measured 'phenotypes' to be associated with new 'genotypes' and/or fairer payment types The future of non-invasive techniques or imaging will certainly consider 'new' phenotypes, which are of interest for animal 
breeders, and need attention for next generations of farm animals, such as lean meat and fat deposition efficiency (Martinsen et al., 2014). Most often these will be traits, which could not be recorded routinely without the application of non-invasive techniques like, for example, traits related to leg health. New selectable leg health traits could be bone mineral content or bone mineral density derived by DXA and/or CT (Charuta et al., 2012; Laenoi et al., 2012; Rangkasenee et al., 2013, Rothammer et al., 2014) or osteochondrosis scores as suggested by Aasmundstad et al. (2013), with a promising heritability estimate of 0.31 $( \pm 0.09)$. Several groups are already trying to implement meat and partially fat quality (water proportion in fat) measurements in vivo. Beef cattle breeders have been using US imaging in order to measure muscle marbling for several years now, whereas CT scanning is being studied in order to measure the IMF content in sheep and pigs during performance testing in vivo, without sacrificing the potential high EBV sire or dam breeding animals. More futuristic, but not less relevant, traits could be the volume of (internal) organs as an indicator of the metabolic capacity of breeding animals or a number of morphological traits under indirect selection pressure by present or future breeding objectives (Kongsro personal communication 2012 to 2014, Carabús et al., 2013). Bünger (personal communication 2013 and 2014) suggests to including more 3D information about muscularity of the gigot, as well as the longissimus dorsi muscles or other body parts, for UK sheep breeding programs. Other traits could be, for example, the number of vertebrae counted using $\mathrm{CT}$ (Donaldson et al., 2013), the gut or rumen size as an indicator of greenhouse gas output (Goopy et al., 2014) and, for example, pelvic dimensions as indictors for ease of lambing.

In addition, the combination of exact phenotypic data derived from non-invasive techniques in combination with (whole) genome data will provide more knowledge and deeper insight into the control of growth and body/carcass composition of farm animals (Cavanagh et al., 2010; Rothammer et al., 2014). In particular, phenotypic traits, which are difficult and expensive to measure as the ones derived from the non-invasive techniques discussed in this review, will provide extra value for genomic selection (Hayes et al., 2013).

In general, it seems that non-invasive (imaging) methods have become common practice in the growing scientific community and partly in breeding organizations and abattoirs, like the development of an on-line CT for carcass classification in Denmark.

\section{Acknowledgments}

This invited review is based on an invited presentation at the 64rd Annual Meeting of the European Association for Animal Production held in Nantes, France, August 2013, and has been supported by the EU COST action FA1102 (FAIM).

\section{Supplementary material}

To view supplementary material for this article, please visit http://dx.doi.org/10.1017/S1751731115000336.

\section{References (Since 2010) ${ }^{2}$}

Aasmundstad T, Kongsro J, Wetten M, Dolvik NI and Vangen 0 2013. Osteochondrosis in pigs diagnosed with computed tomography: heritabilities and genetic correlations to weight gain in specific age intervals. Animal 7, 15761582.

Addeman BT, Kutty S, Perkins TG, Soliman AS, Wiens CN, McCurdy CM, Beaton MD, Hegele RA and McKenzie CA 2015. Validation of volumetric and single-slice MRI adipose analysis using a novel fully automated segmentation method. Journal of Magnetic Resonance Imaging 41, 233-241.

Anton I, Zsolnai A, Holló I, Repa I and Holló G 2013. Effect of TG gene polymorphism on the intramuscular fat content in cattle examined by CT and Soxhlet methods. Archiv Tierzucht 56, 59-66.

Arthur PF, Barchia IM, Giles LR and Eamens GJ 2011. Chemical composition of growing pigs and its relationship with body tissue composition assessed by X-ray-computed tomography. Journal of Animal Science 89, 39353944.

Ayuso D, González A, Hernández F, Corral JM, Izquierdo M 2013. Prediction of carcass composition, ham and foreleg weights, and lean meat yields of Iberian pigs using ultrasound measurements in live animals. Journal of Animal Science 91, 1884-1892.

Barbero A, Astiz S, Lopez-Bote CJ, Perez-Solana ML, Ayuso M, Garcia-Real I and Gonzalez-Bulnes A 2013. Maternal malnutrition and offspring sex determine juvenile obesity and metabolic disorders in a swine model of leptin resistance. Public Library of Science ONE 8, e78424.

Baulain U 2013. Body composition of farm animals by MRI. In Farm animal imaging Dublin 2012 (ed. C Maltin, C Craigie and L Bünger), pp. 16-19. Quality Meat Scotland, Ingliston, UK.

Baulain U, Schön A, Brandt $H$ and Brade W 2011. Leistungsstand der niedersächsischen Schafzucht dargestellt anhand von Ergebnissen der stationären Nachkommenprüfung von 1993 bis 2007. Züchtungskunde 83, 439-450.

Bernau M, Kremer PV and Scholz AM 2013. Vergleich der Körperzusammensetzung von Schweinen bei $80 \mathrm{~kg}$ und $100 \mathrm{~kg}$ Lebendmasse mittels Magnetresonanztomographie. Züchtungskunde 85, 430-439.

Bernau M, Kremer PV, Lauterbach E, Tholen E, Pappenberger E and Scholz AM 2015. Evaluation of carcass composition of intact boars using linear measurements from performance testing, dissection, dual energy X-ray absorptiometry (DXA) and magnetic resonance imaging (MRI). Meat Science. doi:10.1016/j. meatsci.2015.01.011; in press.

Bonin MN, Ferraz JBS, Silva SL, Gomes RC, Cucco DC, Silva Neto PZ, Santana ML Jr, Eler JP, Oliveira ECM, Pedrosa VB, Oliveira PS and Groeneveld E 2010. Genetic parameters for body measurements and ultrasound carcass traits in Nellore cattle. Proceedings 9th World Congress on Genetics Applied to Livestock Production, Leipzig, DE.

Branscheid W, Judas M and Höreth R 2011. Zur Klassifizierung von Schweinehälften: Neue Schätzformeln und neue Geräte. Mitteilungsblatt Fleischforschung Kulmbach 50, 9-28.

Bünger L, Macfarlane JM, Lambe NR, Conington J, McLean KA, Moore K, Glasbey CA and Simm G 2011. Use of X-ray computed tomography (CT) in UK sheep production and breeding. CT scanning - techniques and applications (ed. S Karuppasamy), pp. 329-348. INTECH Europe, Rijeka, Croatia.

Caetano SL, Savegnago RP, Boligon AA, Ramos SB, Chud TCS, Lôbo RB and Munari DP 2013. Estimates of genetic parameters for carcass growth and reproductive traits in Nellore cattle. Livestock Science 155, 1-7.

Carabús A, Gispert M, Muñoz I, Čandek-Potokar M and Font-i-Furnols M 2013. Testes characteristics of entire and immunocastrated male pigs from 30 to $120 \mathrm{~kg}$ live weight measured in vivo with computed tomography. In Farm animal imaging Kaposvar 2013 (ed. C Maltin, C Craigie and L Bünger), pp. 38-41. Quality Meat Scotland, Ingliston, UK.

Case LA, Wood BJ and Miller SP 2012. The investigation of ultrasound technology to measure breast muscle depth as a correlated trait to breast meat yield in turkey (Meleagris gallopavo). Journal of Animal Science 90, 3410-3417.

Cavanagh $C R$, Jonas $E$, Hobbs $M$, Thomson PC, Tammen I and Raadsma HW 2010. Mapping quantitative trait loci (QTL) in sheep. III. QTL for carcass composition traits derived from CT scans and aligned with a meta-assembly for sheep and cattle carcass QTL. Genetics Selection Evolution 42, 36.

\footnotetext{
${ }^{2}$ References before 2010 in Supplementary Material S1.
} 
Chang J, Jung J, Lee H, Chang D, Yoon J and Choi M 2011. Computed tomographic evaluation of abdominal fat in minipigs. Journal of Veterinary Science $12,91-94$.

Charuta A, Cooper RG, Pierzchała M and Horbańczuk JO 2012. Computed tomographic analysis of tibiotarsal bone mineral density and content in turkeys as influenced by age and sex. Czech Journal of Animal Science 57, 573-580.

Choi JG, Cho Cl, Choi IS, Lee SS, Choi TJ, Cho KH, Park BH and Choy YH 2013. Genetic parameter estimation in seedstock swine population for growth performances. Asian-Australasian Journal of Animal Sciences 26, 470-475.

Christensen LB and Angel JAB 2013. Inter-laboratory comparison of medical computed tomography (CT) scanners for industrial applications in the slaughterhouses. In Farm animal imaging Kaposvar 2013 (ed. C Maltin, C Craigie and L Bünger), pp. 27-32. Quality Meat Scotland, Ingliston, UK.

Clelland N, Bünger L, McLean KA, Knott S and Lambe NR 2013. Prediction of intramuscular fat in Texel lamb loins using different $x$-ray computed tomography (CT) scanning techniques. In Farm animal imaging Kaposvar 2013 (ed. C Maltin, C Craigie and L Bünger), pp. 53-56. Quality Meat Scotland, Ingliston, UK.

Collewet G, Bugeon J, Idier J, Quellec S, Quittet B, Cambert M and Haffray P 2013. Rapid quantification of muscle fat content and subcutaneous adipose tissue in fish using MRI. Food Chemistry 138, 2008-2015.

Culjat MO, Goldenberg D, Tewari P and Singh RS 2012. A review of tissue substitutes for ultrasound imaging. Ultrasound in Medicine and Biology 36, 861-873.

Daumas G, Donko T and Monziols M 2013. Identification of possible and relevant post mortem reference methods for carcass composition. In Farm animal imaging Kaposvar 2013 (ed. C Maltin, C Craigie and L Bünger), pp. 14-17. Quality Meat Scotland, Ingliston, UK.

de Genova Gaya L 2013. Genetic variability in ultrasound records of breast muscle in a broiler breeding program. Natural Science 5, 1-4.

Donaldson CL, Lambe NR, Maltin CA, Knott $S$ and Bunger L 2013. Between and within breed variations of spine characteristics in sheep. Journal of Animal Science 91, 995-1004.

Elzo MA, Johnson DD, Lamb GC, Maddock TD, Myer RO, Riley DG, Hansen GR, Wasdin JG and Driver JD 2010. Heritabilities and genetic correlations between postweaning feed intake, growth, and ultrasound traits in a multibreed AngusBrahman cattle population in the subtropics. Proceedings of the 9th World Congress on Genetics Applied to Livestock Production, Leipzig, DE.

Emenheiser JC, Greiner SP, Lewis RM and Notter DR 2010. Longitudinal changes in ultrasonic measurements of body composition during growth in Suffolk ram lambs and evaluation of alternative adjustment strategies for ultrasonic scan data. Journal of Animal Science 88, 1341-1348.

England JA, Salas C, Ekmay RD and Coon CN 2012. Dual energy X-ray absorptiometry analysis of broiler breeder eggs for prediction of egg components and evaluation of egg shell quality. International Journal of Poultry Science 11, 316-325. Font-i-Furnols M, Brun A, Tous N and Gispert M 2013. Use of linear regression and partial least square regression to predict intramuscular fat of pig loin computed tomography images. Chemometrics and Intelligent Laboratory Systems $122,58-64$.

Frisullo P, Marino R, Laverse J, Albenzio M and Del Nobile MA 2010. Assessment of intramuscular fat level and distribution in beef muscles using X-ray microcomputed tomography. Meat Science 85, 250-255.

Fulladosa E, Santos-Garcés E, Picouet P and Gou P 2010. Prediction of salt and water content in dry-cured hams by computed tomography. Journal of Food Engineering 96, 80-85.

Fürst-Waltl B and Grill L 2013. Prerequisites for the implementation of breeding value prediction for sheep. Universität für Bodenkultur, Wien, Austria. Retrieved April 24, 2014, from https://www.dafne.at/dafne_plus_homepage/ download.php?t=ProjectReportAttachment\&k=3248.

Gaunt AP, Morris RH and Newton MI 2013. Magnetic resonance imaging: a too for pork pie development. Foods 2, 393-400.

Gjerlaug-Enger E, Nordbø $\varnothing$ and Grindflek E 2014. Genomic selection in pig breeding for improved meat quality. Proceedings of the 10th World Congress of Genetics Applied to Livestock Production, Vancouver, CA.

Gjerlaug-Enger E, Kongsro J, Ødegard J, Aass L and Vangen 0 2012. Genetic parameters between slaughter pig efficiency and growth rate of different body tissues estimated by computed tomography in live boars of Landrace and Duroc. Animal 6, 9-18.

Goopy JP, Donaldson A, Hegarty R, Vercoe PE, Haynes F, Barnett M and Hutton Oddy V 2014. Low-methane yield sheep have smaller rumens and shorter rumen retention time. British Journal of Nutrition 111, 578-585.
Grosso JLBM, Eler JP, Balieiro JCC, Ferraz JBS, Mattos EC and Michelan Filho T 2010. Genetic correlation for real-time ultrasound and fleshing of breast muscle with carcass traits in broilers. Proceedings of the 9th World Congress on Genetics Applied to Livestock Production, Leipzig, DE.

Gyovai P, Nagy I, Gerencsér Z, Matics Z, Radnai I, Donkó T, Bokor Á, Farkas J and Szendrő Z 2012. Genetic parameters for litter weight, average daily gain and thigh muscle volume measured by in vivo computer tomography technique in Pannon White rabbits. Livestock Science 144, 119-123.

Halliwell M 2010. A tutorial on ultrasonic physics and imaging techniques. Journal of Engineering in Medicine 224, 127-142.

Harangi S 2013. Application of ultrasound measurement technique to evaluate the meat producing ability and carcass value of beef cattle. PhD Thesis, University of Debrecen, Hungary.

Hausman GJ, Basu U, Du M, Fernyhough-Culver M and Dodson MV 2014. Intermuscular and intramuscular adipose tissues - bad $v$. good adipose tissues. Adipocyte 3 (4), 1-14.

Hayes BJ, Lewin HA and Goddard ME 2013. The future of livestock breeding: genomic selection for efficiency, reduced emissions intensity, and adaptation. Trends in Genetics 29, 206-214.

Haynes FEM, Greenwood PL, Siddell JP, McDonagh MB and Oddy VH 2010. Computer tomography software program 'Osirix' aids prediction of sheep body composition. Proceedings of the Australian Society of Animal Production 28, 49. Ho H, Hunter P and Pearson G 2013. Parametric representation of lamb carcasses based on computed tomography (CT) images. In Farm animal imaging Kaposvar 2013 (ed. C Maltin, C Craigie and L Bünger), pp. 76-79. Quality Meat Scotland, Ingliston, UK.

Holló G, Barna B and Nuernberg K 2014. Characterisation of carcass composition and meat quality of male suckling buffalo calves kept on natural grassland. Archiv Tierzucht 56, 107.

Hunter TE, Suster D, Dunshea FR, Cummins LJ, Egan AR and Leury BJ 2011. Dual energy X-ray absorptiometry (DXA) can be used to predict live animal and whole carcass composition of sheep. Small Ruminant Research 100, 143-152.

Jay NP, van de Ven RJ and Hopkins DL 2013. Relationship in lambs between lean weight estimated using CT scanning and VIASCAN ${ }^{\circledR}$. Proceedings of the 59th International Congress of Meat Science and Technology, August 18-23, Izmir, Turkey.

Jeyaruban MG and Johnston DJ 2014. Estimated additive and non-additive breed effects and genetic parameters for ultrasound scanned traits of a multibreed beef Population in tropical Australia. Proceedings of the 10th World Congress of Genetics Applied to Livestock Production, Vancouver, CA.

Jiao S, Maltecca C, Gray KA and Cassady JP 2014. Feed intake, average daily gain, feed efficiency, and real-time ultrasound traits in Duroc pigs: I. Genetic parameter estimation and accuracy of genomic prediction. Journal of Animal Science 92, 2377-2386.

Judas M and Petzet A 2013. Statistical dissection - for which tissues does PLS regression work? In Workshop on Farm Animal and Food Quality Imaging, DTU Compute Technical Report-2013-12, Espoo, Finland, June 17, 11-16.

Kogelman LJA, Kadarmideen HN, Mark T, Karlskov-Mortensen P, Bruun CS, Cirera S, Jacobsen MJ, Jørgensen CB and Fredholm M 2013. An F2 pig resource population as a model for genetic studies of obesity and obesity-related diseases in humans: design and genetic parameters. Frontiers in Genetics I Livestock Genomics 4, 1-14.

Kongsro J and Gjerlaug-Enger E 2013. In vivo prediction of intramuscular fat in pigs using computed tomography. Open Journal of Animal Sciences 3, 321-325.

Kremer PV 2013. In vivo Phänotypisierung von Schlachtkörpermerkmalen bei Schwein und Schaf mittels Magnetresonanztomographie. Habilitation thesis, University of Munich, DE.

Kremer PV, Förster M and Scholz AM 2013. Use of magnetic resonance imaging (MRI) to predict the body composition of pigs in vivo. Animal 7, 879-884.

Kremer PV, Fernández Fígares I, Förster M and Scholz AM 2012. In vivo body composition in autochthonous and conventional pig breeding groups by dual energy $\mathrm{X}$-ray absorptiometry and magnetic resonance imaging under special consideration of Cerdo Ibérico. Animal 6, 2041-2047.

Laenoi W, Rangkasenee N, Uddin MJ, Cinar MU, Phatsara C, Tesfaye D, Scholz AM, Tholen E, Looft C, Mielenz M, Sauerwein H, Wimmers K and Schellander K 2012. Association and expression study of MMP3, TGF $\beta 1$ and COL10A1 as candidate genes for leg weakness-related traits in pigs. Molecular Biology Reports 39, 3893-3901. 
Laursen LF, Bærentzen JA, Igarashi T, Petersen MK, Clemmensen LKH, Ersbøll BK and Christensen LB 2013. PorkCAD: case study of the design of a pork product prototype. In Proceedings of the 5th International Congress of International Association of Societies of Design Research, Tokyo, Japan, August 26-30. Retrieved February 19, 2015, from http://design-cu.jp/iasdr2013/papers/1134-1b.pdf.

Lee JH, Lee YM, Oh S-H, Son HJ, Jeong DJ, Whitley N and Kim JJ 2014. Estimation of genetic parameters for real-time ultrasound measurements for Hanwoo cows at different ages and pregnancy status. Asian Australasian Journal of Animal Science 27, 155-160.

Ley $C$ 2013. Pig genetics is all about sustainable profitability. Pig International 43, 4-7.

Liao JJZ and Capen R 2011. An improved Bland-Altman method for concordance assessment. The International Journal of Biostatistics 7, Art. 9, 1-17.

Lösel D, Kremer P, Albrecht E and Scholz AM 2010. Comparison of a GE Lunar DPX-IQ and a Norland XR-26 dual energy X-ray absorptiometry scanner for body composition measurements in pigs - in vivo. Archiv Tierzucht 53, 162-175.

Magnusson M, Malusek A, Muhammad A and Alm Carlsson G 2011. Determination of quantitative tissue composition by iterative reconstruction on 3D DECT volumes. Proceedings of the 11th International Meeting on Fully ThreeDimensional Image Reconstruction in Radiology and Nuclear Medicine, Potsdam, DE, 120-123.

Maignel L, Daigle JP, Gariépy C, Wilson D and Sullivan B 2010. Prediction of intramuscular fat in live pigs using ultrasound technology and potential use in selection. Proceedings of the 9th World Congress on Genetics Applied to Livestock Production, Leipzig, DE.

Martinsen KH, Ødegård J, Olsen D and Meuwissen THE 2014. Genetic variation in efficiency to deposit lean meat and fat in Norwegian Landrace pigs. Proceedings of the 10th World Congress of Genetics Applied to Livestock Production, Vancouver, Canada.

Maximini L, Brown DJ, Baumung R and Fuerst-Waltl B 2012. Genetic parameters of ultrasound and computer tomography scan traits in Austrian meat sheep. Livestock Science 146, 168-174.

Milisits G, Donkó T, Dalle Zotte A, Sartori A, Szentirmai E, Emri M, Opposits G Orbán A, Pőcze 0, Repa I and Sütő Z 2013. Application of computed tomography to assess the effect of egg yolk ratio on body composition in chickens of different genotype and gender at hatch and during the rearing period. British Poultry Science 54, 611-619.

Mitchell AD, Ramsay TG and Scholz AM 2012. Measurement of changes in body composition of piglets from birth to $4 \mathrm{~kg}$ using quantitative magnetic resonance (QMR). Archiv Tierzucht 55, 64-67.

Monziols M, Rossi A and Daumas G 2013. Impact of pig population (light or heavy) on computed tomography (CT) and dissection relationship for lean meat percentage measurement. In Farm animal imaging Kaposvar 2013 (ed. C Maltin C Craigie and L Bünger), pp. 22-26. Quality Meat Scotland, Ingliston, UK.

Moore K, McLean KA and Bunger L 2011. The benefits of computed tomography (CT) scanning in UK sheep flocks for improving carcase composition. Proceedings of the British Society of Animal Science and the Association of Veterinary Teaching and Research Work, April 4-5, Nottingham. Advances in Animal Biosciences 2, 10.

Mortimer SI, Swan AA, Brown DJ and van der Werf JHJ 2014. Genetic parameters revisited for ultrasound scanning traits in Australian sheep. Proceedings of the 10th World Congress of Genetics Applied to Livestock Production, Vancouver, CA.

Nagy I, Gyovai P, Radnai I, Matics Z, Gerencsér Z, Donkó T and Szendrő Z 2010. Genetic parameters of growth in vivo CT based and slaughter traits in Pannon white rabbits. Proceedings of the 9th World Congress on Genetics Applied to Livestock Production, Leipzig, DE.

Navajas EA, Richardson RI, Fisher AV, Hyslop JJ, Ross DW and Prieto N 2010. Predicting beef carcass composition using tissue weights of a primal cut assessed by computed tomography. Animal 4, 1810-1817.

OECD/Food and Agriculture Organization of the United Nations 2014. OECDFAO agricultural outlook 2014. OECD Publishing, 2, rue André-Pascal, 75775 PARIS CEDEX 16. Retrieved February 19, 2015, from http://dx.doi.org/10.1787/ agr_outlook-2014-en.

Olsen EV and Christensen LB 2013. Comparison of accuracy of reference methods based on CT and manual dissection. In Farm animal imaging Kaposvar 2013 (ed. C Maltin, C Craigie and L Bünger), pp. 18-21. Quality Meat Scotland, Ingliston, UK.

Pathak V, Singh VP and Sanjay Y 2011. Ultrasound as a modern tool for carcass evaluation and meat processing: a review. International Journal of Meat Science 1, 83-92.

Pérez-Palacios T, Caballero D, Caro A, Rodríguez PG and Antequera T 2014. Applying data mining and computer vision techniques to MRI to estimate quality traits in Iberian hams. Journal of Food Engineering 131, 82-88.

Picouet PA, Teran F, Gispert M, Font-i-Furnols M 2010. Lean content prediction in pig carcasses, loin and ham by computed tomography (CT) using a density model. Meat Science 86, 616-622.

Pillen S and van Alfen N 2011. Skeletal muscle ultrasound. Neurological Research 33, 1016-1024.

Pinheiro TR, Mercadante MEZ, Albuquerque LG, Cyrillo JNSG and Branco RH 2011. Phenotypic and genetic parameters compared during repeated measures of longissimus muscle area and subcutaneous fat thickness in Nelore cattle. Genetics and Molecular Research 10, 2944-2952.

Rangkasenee N, Murani E, Brunner R, Schellander K, Scholz AM, Luther H, Hofer A, Ponsuksili $S$ and Wimmers K 2013. KRT8, FAF1 and PTH1R gene polymorphisms are associated with leg weakness traits in pigs. Molecular Biology Reports 40, 2859-2866.

Ravagnolo O, Brito G, Aguilar I, Ciappesoni G and Lema M 2010. Genetic parameters for ultrasound live traits in pasture fed Angus cattle. Proceedings of the 9th World Congress on Genetics Applied to Livestock Production, Leipzig, DE. Ribeiro FRB, Tedeschi LO, Rhoades RD, Smith SB, Martin SE and Crouse SF 2011. Evaluating the application of dual $\mathrm{X}$-ray energy absorptiometry to assess dissectible and chemical fat and muscle from the $9^{\text {th }}$-to- $11^{\text {th }}$ rib section of beef cattle. The Professional Animal Scientist 27, 472-476.

Rothammer S, Kremer PV, Bernau M, Fernandez-Figares I, Pfister-Schär J, Medugorac I and Scholz AM 2014. Genome-wide QTL-mapping of nine body composition and bone mineral density traits in pigs. Genetics Selection Evolution 46,68 .

Salas C, Ekmay RD, England J, Cerrate S and Coon CN 2012. Determination of chicken body composition measured by dual energy X-ray absorptiometry. International Journal of Poultry Science 11, 462-468.

Scholz AM and Mitchell AD 2010. Body composition: indirect measurement. In Encyclopedia of animal science, 2nd edition. (ed. DE Ullrey, CK Baer and WG Pond), pp. 152-156. CRC Press, Boca Raton, FL, USA.

Scholz AM, Kremer PV, Wenczel R, Pappenberger E and Bernau M 2013. Body composition in farm animals by dual energy X-ray absorptiometry. In Farm animal imaging Dublin 2012 (ed. C Maltin, C Craigie and L Bünger), pp. 9-14. Quality Meat Scotland, Ingliston, UK.

Simeonova ML, Todorov NA and Schinckel AP 2012. Review of in vivo-methods for quantitative measurement of protein deposition rate in animals with emphasize on swine. Bulgarian Journal of Agricultural Science 18, 455-481.

Szendrő Z, Metzger S, Nagy I, Szabó A, Petrási Z, Donkó T and Horn P 2012. Effect of divergent selection for the computer tomography measured thigh muscle volume on productive and carcass traits of growing rabbits. Livestock Science 149, 167-172.

Szentirmai E, Milisits G, Donkó T, Budai Z, Ujvári J, Fülöp T, Repa I and Sütő Z 2013. Comparison of changes in production and egg composition in relation to in vivo estimates of body weight and composition of brown and white egg layers during the first egg-laying period. British Poultry Science 54, 587-593.

Van de Sompel D, Sasportas LS, Dragulescu-Andrasi A, Bohndiek S and Gambhir SS 2012. Improving image quality by accounting for changes in water temperature during a photoacoustic tomography scan. Public Library of Science ONE 7, e45337.

Wang ZM, Heymsfield SB, Chen Z, Zhu S and Pierson RN 2010. Estimation of percentage body fat by dual-energy x-ray absorptiometry: evaluation by in vivo human elemental composition. Physics in Medicine and Biology 55, 2619-2635.

Zurl B, Tiefling R, Winkler P, Kindl P and Kapp KS 2014. Hounsfield units variations: impact on CT-density based conversion tables and their effects on dose distribution. Strahlentherapie und Onkologie 190, 88-93. 